\title{
SELF EFFICACY PELAKU BUANG AIR BESAR SEMBARANGAN DI KOTA PEKALONGAN (MODEL REKAYASA PERILAKU DAN JAMBAN TRIPIKON SEBAGAI LANGKAH PERCEPATAN PENCAPAIAN 100\% ODF DI KOTA PEKALONGAN)
}

\author{
Rr. Vita Nurlatif, Ardiana Priharwanti*, Jaya Maulana \\ Prodi Kesehatan Masyarakat Universitas Pekalongan \\ Jalan Sriwijaya Nomor 3 Pekalongan \\ Korespondensi: diana.arif25@gmail.com
}

\begin{abstract}
Pekalongan City targets in 2019 all villages with ODF status, so that Pekalongan City can be achieved $100 \%$ of open defecation. This strategic step must continue to be pursued, considering that as of March 2019 there were still 14 villages that had not yet reached 100\% ODF, namely: Kelurahan Tirto, Pringrejo, Pasirkratonkramat, Kalibaros, Setono, Gamer, Panjang Baru, Panjang Wetan, Padukuhan Kraton, Bandengan, Krapyak, Degayu, Jenggot and Sokoduwet (Dinas Kesehatan, 2019). $B A B S$ behavior and unreachable pillars of STBM have an impact on the high increase in cases of environmental-based diseases. The results of Restu Prasetyo, et al., 2017 in the Indonesian Population journal found that 1 in 25 children under five suffer from diarrhea each year. This research method uses qualitative design with in-depth interviews with key informants and triangulation totaling 28 people consisting of village heads and BABS actors at the research locus. Data collection is done by in-depth interviews and observations. Data processing uses the stages of reduction, narrative building and pattern matching. The results of the mapping of the causes of the problem of not achieving 100\% ODF at 14 loci due to 4 aspects (environment, behavior, and health services), in addition the results of the study found two approaches to the acceleration of 100\% ODF through behavioral engineering and the application of Tripikon WC in areas with tidal conditions. Conclusion 1. The causes of BABS (defecation) in Pekalongan City are three things seen from the environmental aspect (tidal conditions, settlements close to streams or rice fields / gardens), behavior (the perpetrators are not accustomed to using the family toilet) and also services health (there is still no massive BABS stop campaign, and there is no elaboration from other agencies related to the achievement of ODF in Pekalongan City), 2. Two models are formulated, namely the behavioral engineering model and Tripikon toilet to accelerate 100\% ODF in Pekalongan City. Suggestions for adopting behavioral engineering models and the application of Tripikon WC in rob affected areas require close collaboration and synergy (Government, Community, Higher Education, and Private) to implement them.
\end{abstract}

Keyword: Model, behavioral engineering, tripikon toilet, $O D F$

\section{PENDAHULUAN}

Kota Pekalongan menargetkan di tahun 2019 seluruh kelurahan berstatus ODF, sehingga dapat tercapai Kota Pekalongan $100 \%$ bebas buang air besar sembarangan. Target ini masih harus terus diupayakan langkah strategisnya, mengingat sampai dengan bulan Maret 2019 masih terdapat 14 Kelurahan yang belum mencapai ODF 100\%, yaitu : Kelurahan Tirto, Pringrejo, Pasirkratonkramat, Kalibaros, Setono, Gamer, Panjang Baru, Panjang Wetan, Padukuhan Kraton, Bandengan, Krapyak, Degayu, Jenggot dan Sokoduwet (Dinas Kesehatan, 2019).

Hal ini tidak hanya terkait dengan keberadaan sarana prasarana saja yaitu jamban maupun penyediaan air bersih, akan tetapi lebih kepada aspek Behaviour, yaitu perilaku masyarakat yang tidak kompromis dengan perilaku hidup bersih dan sehat, meskipun telah memiliki jamban masih banyak yang melakukan kebiasaan untuk buang air besar di sungai maupun kebun.

Perilaku BABS dan ketidak tercapaian pilar-pilar STBM berdampak terhadap tingginya peningkatan kasus penyakit berbasis lingkungan. Hasil penelitian Restu Prasetyo, et al, tahun 2017 dalam jurnal Kependudukan Indonesia menemukan bahwa 1 dari 25 balita menderita diare tiap tahunnya. 
Guna percepatan ketercapaian $100 \%$ ODF di Kota Pekalongan diperlukan penelitian yang mampu memberikan informasi mengenai peta penyebab masalah belum tercapainya $100 \%$ ODF dan model yang dapat memberikan solusi atas permasalahan tersebut.

\section{METODE}

Desain Penelitian ini menggunakan desain penelitian exploratory research dengan pendekatan kualitatif dengan triangulasi sumber melalui indepth interview pada informan utama, dan informan pendamping untuk mencari apersepsi berbagai sumber. Instrumen penelitian menggunakan Guidence interviewing. subyek penelitian terdiri dari 28 orang informan utama dan pendamping yaitu Lurah dan pelaku BABS pada lokus penelitian yaitu Kelurahan Tirto, Pringrejo, Pasirkratonkramat, Kalibaros, Setono, Gamer, Panjang Baru, Panjang Wetan, Padukuhan Kraton, Bandengan, Krapyak, Degayu, Jenggot dan Sokoduwet. Pengumpulan data menggunakan teknik wawancara mendalam dengan upaya triangulasi sumber dan metode. Sedangkan pengolahan data melalui pentahapan reduksi, naratif building dan pattern matching.

\section{HASIL DAN PEMBAHASAN}

Berdasarkan hasil penelitian ditemukan beberapa point penting, yaitu :

\subsection{Analisis Peta penyebab ketidaktercapaian $100 \%$ ODF}

Berdasarkan hasil penelitian, ditemukan tiga aspek penyebab ketidaktercapaian $100 \%$ ODF di Kota Pekalongan, yaitu :

a) Aspek Lingkungan

Pada aspek lingkungan,kondisi geografis yang tidak mendukung, kondisi rob, dekat bantaran sungai, terdapat areal perkebunan luas dan rindang menjadi pemicu /trigger masyarakat berperilaku atau bergeser perilakunya pada kecenderungan BABS.

b) Aspek perilaku

Pada aspek perilaku dipetakan bahwa perilaku BABS pada 14 lokus dikarenakan : telah dianggap bukan perilaku yang menyimpang dari norma baku, sikap permisifitas masyarakat, keluarga, beberapa contoh adopsi perilaku sosial yang dimotori oleh tokoh setempat, dan maindset yang menganggap tidak ada kontribusi positif antara BABS dengan penyakit berbasis lingkungan dan gangguan kesehatan yang lainnya, tingkat pendidikan, tingkat pendapatan, dan pemahaman yang belum cukup baik tentang ODF, yang disertai dengan pemahaman yang belum cukup baik mengenai BABS tidak sejalan dengan pemahaman kebersihan sebagian dari iman menjadi trigger dalam ketidaktercapaian ODF $100 \%$, adanya pemahaman bahwa pola perilaku akan berubah dengan syarat didukung dengan faspras terlebih dahulu juga menjadi salah satu penyebab.

c) Aspek pelayanan kesehatan :

Pada aspek pelayanan kesehatan, diartikan sebagai berbagai upaya yang telah dilakukan baik oleh pihak kelurahan yang berkerja sama dengan babinkamtibmas, BKM, LMD, maupun dengan Dinas Kesehatan, seperti : upaya sosialisasi ODF, pemasangan spanduk, perobohan WC cemplung, pemberian bantuan WC, penyediaan faspras jamban komunal, elaborasi dengan program kotaku, dan lain sebagainya. Akan tetapi dalam pemetaan masalah ini diartikan sebagai kendala program yang dihadapi dapat dipetakan di antaranya adalah : belum adanya elaborasi dengan OPD lintas sektor dikarenakan adanya perbedaan sudut pandang prioritas program pada masing masing OPD lintas sektor.

Dari temuan tiga aspek penyebab ketidaktercapaian 100\% ODF di Kota Pekalongan, maka dirumuskan dua model guna mempercepat pencapaian 100\% ODF 
di Kota Pekalongan, yaitu melalui model rekayasa perilaku dan model Jamban Tripikon yang dapat diadopsi pada wilayah terdampak rob.

\subsection{Model rekayasa perilaku}

Perubahan perilaku menuju bebas BABS (Buang Air Besar Sembarangan) guna mencapai 100\% ODF (Open Defecation Free) di Kota Pekalongan, dapat dilaksanakan dengan mengadopsi Model Teori Perubahan perilaku Transtheoritical Model of Behavioural Change yang dikembangkan oleh Prochasca dan Diclemente di tahun 1982, di mana teori ini merupakan perpaduan dari 18 teori pendekatan untuk merubah perilaku. Model ini dipilih dengan beberapa pertimbangan yang sesuai dengan kultur masyarakat Kota Pekalongan, di antaranya model ini memiliki aspek aspek :

a) Model rekayasa perilaku ini menitik beratkan pada model perubahan perilaku bertahap.

b) Model rekayasa perilaku ini merupakan model yang disengaja diberlakukan untuk merubah maindset atau perilaku.

c) Model ini didasarkan pada pengambilan keputusan oleh individu.

d) Model ini melibatkan kognisi, emosi dan perilaku.

e) Model ini sesuai digunakan sebagai dasar pengembangan intervensi efektif bagi promosi kesehatan.

Adapun tahapan perubahan perilaku menurut adopsi model ini adalah :

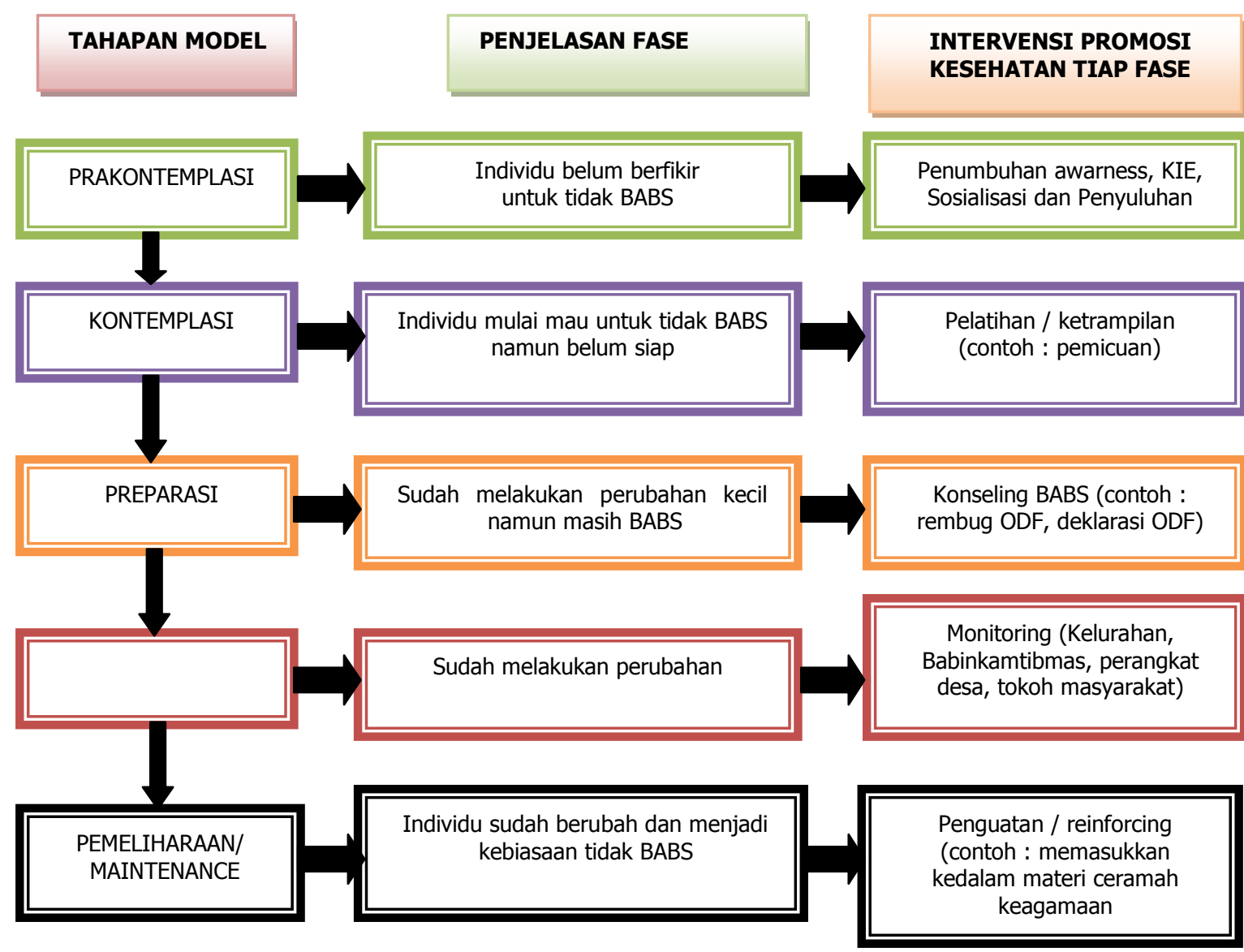

\subsection{Model Jamban Tripikon untuk wilayah terdampak rob}

\subsubsection{Pengertian Tripikon}

Tripikon-S merupakan salah satu alat yang memiliki fungsi seperti septic tank untuk mengatasi masalah sanitasi pada suatu daerah yang memiliki lahan yang sempit/rawa. 
Tripikon-S ini diaplikasikan kepada masyarakat tepi laut sebagai solusi sanitasi untuk mencegah feses ke badan laut sekaligus mencegah pencemaran oleh bakteri Escherichia coli. Tripikon-S atau Tiga Pipa Konsentris-Septik adalah septic tank vertikal yang terdiri dari tiga pipa utama yang digunakan secara konsentris atau ditempatkan dengan titik pusat yang sama, Tiga pipa utama tersebut terdiri dari ukuran yang berbeda yaitu pipa kecil, pipa sedang dan pipa besar.Septic tank Tripikon-S digunakan untuk perumahan yang berada di daerah perairan, seperti sungai atau rawa. Hal ini dilatarbelakangi ketidaktersediaan lahan untuk membuat septic tank konvensional, karena kondisi perumahan yang berada di atas perairan.

(Diakses dari https://dinkes.papuabaratprov.go.id/2018/09/tripikon-s-apakah-itu/)

\subsubsection{Cara Kerja}

Pengolahan yang terjadi dalam T-Pikon-H ini adalah secara semiaerob dan anaerob. Konsep dasar pengolahan adalah dengan menggunakan 3 pipa, yaitu: pipa kecil sebagai inlet dari toilet, pipa medium sebagai tempat terjadinya proses dekomposisi biologis, dan pipa sbesar sebagai pelimpah (overflow) efluen. Ketiga pipa tersebut diatur secara konsentris. Kinerja kedua sistem ini masih perlu dikaji lebih lanjut, namun bila dilihat dari ide pengolahannya, maka sistem ini dapat menjadi salah satu alternatif pengolahan air limbah yang potensial untuk dikembangkan.

Konstruksi Tripikon-S terdiri dari 3 buah pipa penguraian hampir sama dengan tanki septik konvensional. Limbah padat dan cair masuk melalui pipa kecil dan mengalami penguraian di dalam pipa sedang. Bagian atas dari pipa sedang merupakan tempat terjadinya proses aerobic, bagian tengah merupakan lintasan dan bagian bawah merupakan tempat terjadinya proses anaerobic. Selama melintas di pipa tengah, limbah akan terurai menjadi gas, air, dan lumpur mineral. Waktu penguraian sekurang-kurangnya 3 hari.Pipa yang terletak paling dalam merupakan pipa yang paling kecil dengan ukuran diameter $5 \mathrm{~cm}$ yang dihubungkan dengan jamban leher angsa dari jamban rumah tangga. Di luar pipa $5 \mathrm{~cm}$ dipasang pipa sedang dengan ukuran 15 - $25 \mathrm{~cm}$. Di dalam pipa itu terjadi perombakan limbah rumah tangga. Pada bagian bawah pipa sedang, sekitar 10-20 cm dari dasar, dibuat lubang - lubang berdiameter $1 \mathrm{~cm}$ untuk jalan air dan pada ujung bawah-nya dibuat celah - celah sebesar 1-2 cm yang mengelilingi pipa untuk keperluan pengurasan lumpur tinja.Pipa terluar atau pipa besar dengan ukuran diameter 20-30 cm merupakan pipa peluap. Celah antara pipa sedang dan pipa besar minimal $2 \mathrm{~cm}$. Panjang pipa besar minimum $1 \mathrm{~m}$ dan harus selalu berada di atas permukaan air pasang tertinggi. Salah satu faktor yang menjadi perimbangan dalam pemilihan tipe pengolahan limbah adalah keterbatasanakan tanah. Tripikon-S merupakan salah satu alternatif penanganan air limbah domestik dan industri rumah tangga yang tidak membutuhkan lahan yang luas. 


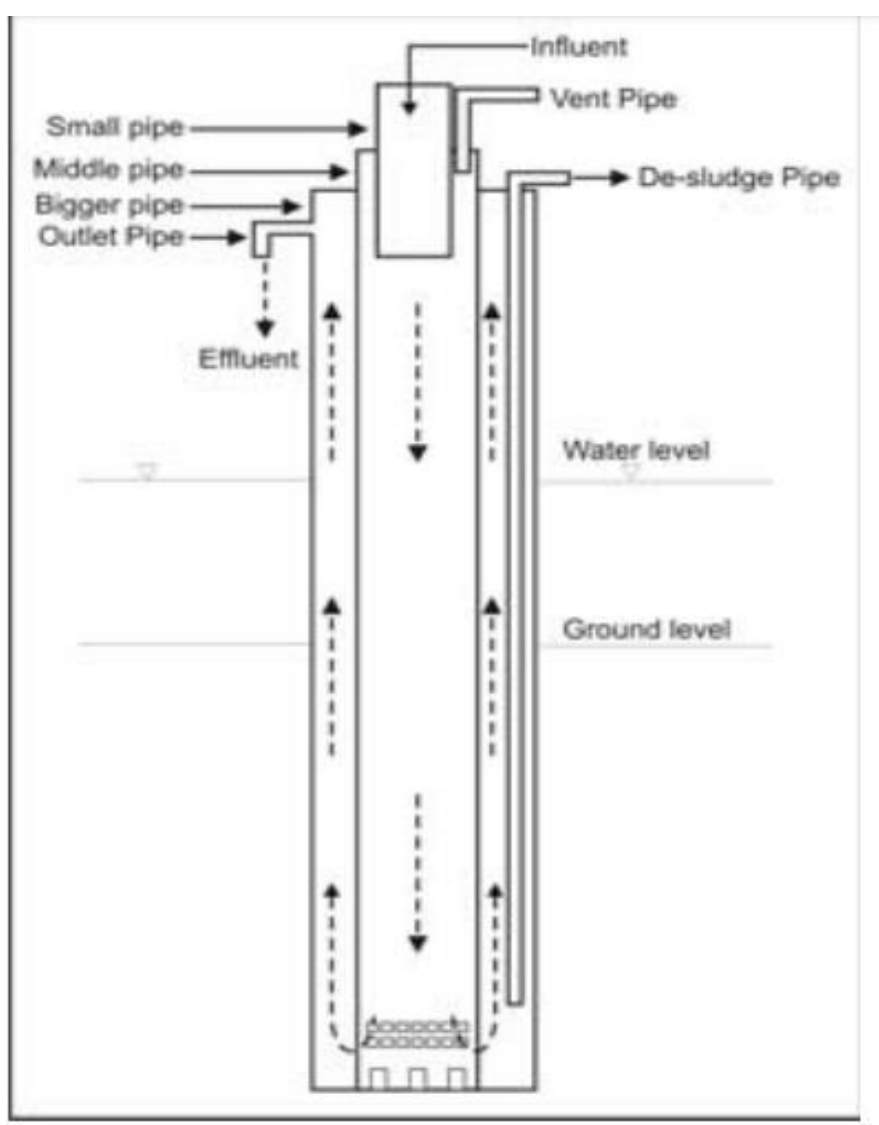

Gambar Model Jamban Tripikon

\section{SIMPULAN DAN SARAN}

\subsection{Simpulan}

Berdasarkan hasil riset dapat disimpulkan sebagai berikut :

a) Penyebab masalah babs (buang air besar sembarangan) di Kota Pekalongan ada tiga hal dilihat dari aspek lingkungan (kondisi rob, pemukiman yang dekat dengan aliran sungai maupun sawah/ kebun), perilaku (ketidakbiasaan pelaku untuk menggunakan jamban keluarga) dan juga layanan kesehatan (masih belum massifnya kampanye stop babs, dan belum adanya elaborasi dari dinas lain terkait dengan pencaapaian ODF di Kota Pekalongan).

b) Model rekayasa perilaku dan jamban Tripikon dapat diadopsi oleh pemerintah Kota Pekalongan sebagai upaya percepatan pencapaian 100\% ODF.

\subsection{Saran}

Adapun saran yang dapat disampaian dalam riset ini adalah:

a) Perlu dibangun komitmen yang kuat dan dilegalkan dengan kebijakan dari pemerintah daerah (Walikota) komitmen ini bukan hanya deklarasi akan tetapi diejewantahkan dalam program masing-masing kedinasan terkait.

b) Perlunya elaborasi antar lembaga akademis, media, dinas kesehatan, dan lembaga pemerintah daerah untuk mengedukasi, membina, mengubah mindset dan meningkatkan kesadaran masyarakat untuk berperilaku sehat dan bersih termasuk menghilangkan babs.

c) Perlu elaborasi lintas sektoral dan menggalang rekanan untuk mempercepat pencapaian ODF di Kota Pekalongan dalam hal ini termasuk pada kemitraan dalam penyediaan sarana prasarana yang memadai serta pendampingan kepada masyarakat.

d) perlu diapliksikan model jamban tripikon untuk menjawab permasalahan jamban di wilayah rob. 


\section{DAFTAR PUSTAKA}

\section{https://dinkes.papuabaratprov.go.id/2018/09/tripikon-s-apakah-itu/}

Delli Noviarti Rachman, PENGGUNAAN TRIPIKON-S SEBAGAI ALTERNATIF PENGGUNAAN SEPTIC TANK DI DAERAH TEPIAN SUNGAI DAN RAWA

Abdul Muhid, d. ( 2018). Perubahan Perilaku Open Defecation Free (ODF) melalui Program Sanitasi Total Berbasis Masyarakat (STBM) di Desa Babad Kecamatan Kedungadem Kabupaten Bojonegoro. ENGAGEMENT Jurnal Pengabdian Kepada Masyarakat ISSN: 2579-8391 (Online) Volume 2, Number 1, Mei, 99-119.

Agus Donny Susanto, d. (2013). Intervensi Problem Solving Cycle (PSC) Berdasarkan 7 Prinsip Menuju Keselamatan Pasien Rumah Sakit. Jurnal Adminstrasi Kebijakan Ksehatan Vol 11 No 2, Mei-Agustus 2013, 76-79.

Anonymous. (2017, Oktober 10). Retrieved April 14, 2019, from https://pegiringan.desa.id/odf-opendefecation-free-atau-stop-buang-air-besar-sembarangan/\#comment-208

$\begin{array}{lllll}\text { Anonymous. } & \text { (2019). } & \text { Retrieved } & \text { April } & \text { 14, }\end{array}$ http://www.pengertianmenurutparaahli.net/page/22/

Anonymous. (n.d.). Sanitasi.net Spirit Of water. Retrieved April 14, 2019, from http://www.sanitasi.net/: http://www.sanitasi.net/sanitasi-total-berbasis-masyarakat.html

Arifianty, D. P. (2017). Peran Pemerintah Lokal Dalam Peningkatan Sanitasi Lingkungan Masyarakat: Studi Tentang Keberhasilan program Open Defecation Free (ODF) di KAbuapten Bojonegoro. Kebijakan dan Manajemen Publik Volume 5, Nomor 3, September - Desember 2017, 1-9

Aspuah, Siti. 2013. Kumpulan KuesionerdanInstrumenPenelitianKesehatan.Yogyakarta :NuhaMedika.

Bungin, Burhan. 2015. Metodologi Penelitian Kualitatif Aktualisasi Metodologis kearah Ragam Varian Kontemporer. Jakarta : PT. Raja Grafindo Persada.

Chandra, B, 2007, Pengantar kesehatan lingkungan, Penerbit Buku Kedokteran EGC, Jakarta

Dahlan, Sopiyudin. 2010. Besar Sampel dan Cara Pengambilan Sampeldalam Penelitian Kedokteran dan Kesehatan. Jakarta : Salemba Medika.

Depkes RI, 2008, Modul Pelatihan Stop Buang Air Besar Sembarangan (STOP BABS), Ditjen PP dan PL bekerjasama dengan Pokja AMPL Pusat, Depkes RI . Jakarta

Depkes. (2008). Depkes.go.id. Retrieved April 15, 2019, from http://inswa.or.id/wpcontent/uploads/2012/07/Strategi-Nasional-Sanitasi-Total-Berbasis-Masyarakat.pdf

Dinkes. (2019 , Maret 12). https://dinkes.pekalongankota.go.id/berita/menuju-kota-pekalonganodf.html. Retrieved November 18, 2019, from

https://dinkes.pekalongankota.go.id/berita/menuju-kota-pekalongan-odf.html:

https://dinkes.pekalongankota.go.id/berita/menuju-kota-pekalongan-odf.html

Kar, K and Chambers, R., 2008, Handbook on Community-Led Total Sanitation, Plan UK, London.

Kemenkes, D. P. (2014). Panduan Praktis Implementasi PPSP melalui Penguatan Pilar-pilar STBM (IPP-STBM). Jakarta: Kementerian Kesehatan RI.

Kemenkes. (2015). Depkes. Retrieved April 14, 2019, from http://www.depkes.go.id/resources/download/RAP\%20Unit\%20Utama\%2020152019/1.\%20Sekjen.pdf

Kemenkes. (2017, Oktober 4). Retrieved April 14, 2019, from http://www.kesmas.kemkes.go.id/assets/upload/dir_60248a365b4ce1e/files/PERENC-

KESMAS-2018-FINAL-Dirjen-Kesmas_906.pdf 
Kepmenkes RI No. 852/Menkes/SK/IX/2008. 2008. Strategi nasional sanitasi total berbasis masyarakat. Depkes RI . Jakarta.

Kesehatan, B. K. (2017, Febuari Senin, 27). www.depkes.go.id. Retrieved April Minggu 14, 2019, from http://www.depkes.go.id/article/print/17022700006/rakerkesnas-2017-integrasi-seluruhkomponen-bangsa-mewujudkan-indonesia-sehat.html

Kotapekalongan dalam angka tahun 2017. Badan Pusat Statistik Kotapekalongan.

Laju pembangunan manusia Kotapekalongan. Tahun 2017. Badan pusat statistik Kotapekalongan.

Menuju Kota Pekalongan ODF. Dinas Kesehatan Kota Pekalongan diakses pada 12 Maret 2019. https://dinkes.pekalongankota.go.id/berita/menuju-kota-pekalongan-odf.html

Mulyasa, E. Implementasi Kurikulum 2004 Panduan Pembelajaran KBK (Bandung: PT Remaja Rosdakarya, 2004), 111.

Nana Sudjana,. Dasar-dasar Proses Belajar Mengajar (Bandung: Sinar Baru Algensindo, 2009), 85-86.

Notoatmodjo, Soekidjo. 2010. Metodologi Penelitian Kesehatan. Jakarta : Rineka Cipta.

Nugraha, M. F. ( 2015). Dampak Program Sanitasi Total Berbasis Masyarakat (STBM) Pilar Pertama di Desa Gucialit Kecamatan Gucialit kabupaten Lumajang. Kebijakan dan Manajemen Publik, 44-53.

Peraturan daerah Kotapekalongan nomor 8 tahun 2017 tentang Rencana Pembangunan jangka menengah daerah Kotapekalongan tahun 2016-2021.

Permenkes. (2014). bkpm.go.id. Retrieved April 14, 2019, from https://peraturan.bkpm.go.id/jdih/userfiles/batang/Permenkes_3_2014.pdf: https://peraturan.bkpm.go.id/jdih/userfiles/batang/Permenkes 3 2014.pdf

Profil kesehatan provinsi jawa tengah tahun 2016. Dinas kesehatan provinsi jawa tengah. Tahun 2016. Website : www.dinkesjatengprov.go.id.

Purnama, S. G. (2017). Penaykit Berbasis Lingkungan. Bali: Unud Press.

Rencana Pembangunan Jangka Menengah Nasional (RPJMN) 2005-2019.

Rencana Pembangunan Jangka Panjang Nasional (RPJPN) 2005-2025.

Restu Prasetyo, dkk. 2017.Determinan Penyakit Berbasis Lingkungan pada Anak Balita di Indonesia. Jurnal Kependudukan Indonesia Vol.12 No.2. DOI: https://doi.org/10.14203/jki.v12i2.266.

Rustika, I. M. (2012). Efikasi Diri: Tinjauan Teori Albert Bandura. Buletin Psikologi Vol 20 No 1-2, $18-25$.

Saryono, dkk. Metodologi Penelitian Kualitatif dan Kuantitatif dalam Bidang Kesehatan. Yogyakarta : Nuha Medika.

Sugiyono. 2015. Statistika untuk Penelitian. Bandung : Alfabeta.

Sutaryo. (2004). In Dasar-Dasar Sosialisasi (p. 156). Jakarta: Jakarta: Rajawali Press.

Syaiful Bahri Djamarah dan Aswan Zain, Strategi Belajar Mengajar, (Jakarta: Rineka Cipta, 2002), 102.

Wikipedia. (2019). Wikipedia Ensiklopedi Bebas. Retrieved April 14, 2019, from https://id.wikipedia.org/wiki/Percepatan: https://id.wikipedia.org/wiki/Percepatan

Yulda, dkk. 2017. Pengaruh Faktor Internal dan Eksternal terhadap Perilaku Buang Air Besar di Jamban Pasca Pemicuan di wilayah kerja Puskesmas Tanjung Batu. Jurnal Ilmu Kesehatan Masyarakat : Universitas Sriwijaya. DOI: https://doi.org/10.26553/jikm.2016.8.2.109-116. 